\title{
A Review of Complement Activation in SLE
}

\author{
Arthur Weinstein $^{1,2,3}$ (D) $\cdot$ Roberta V. Alexander ${ }^{3} \cdot$ Debra J. Zack $^{3}$
}

Accepted: 5 January 2021 / Published online: 10 February 2021

(C) The Author(s) 2021

\begin{abstract}
Purpose of Review Complement activation is a key event in the pathogenesis of tissue inflammation and injury in systemic lupus erythematosus (SLE). This review is aimed at comparing the usefulness of measurement of complement proteins in serum/ plasma $(\mathrm{C} 3, \mathrm{C} 4)$ to complement activation (split) products in plasma and on circulating blood cells for SLE diagnosis, disease monitoring, and prognosis.

Recent Findings Complement split products, $\mathrm{C} 3 \mathrm{dg}$, iC $3 \mathrm{~b}$, and $\mathrm{C} 4 \mathrm{~d}$, are elevated in SLE, and $\mathrm{C} 3 \mathrm{dg} / \mathrm{C} 3$ and $\mathrm{iC} 3 \mathrm{~b} / \mathrm{C} 3$ ratios correlate with active SLE. C4d also is higher in patients with lupus nephritis. An elevated level of the alternative pathway split product, $\mathrm{Bb}$, in early lupus pregnancy is a predictor of adverse outcomes in SLE patients with antiphospholipid antibodies. Elevated levels of cell-bound complement activation products (CB-CAPs), namely, B cell-bound $\mathrm{C} 4 \mathrm{~d}(\mathrm{BC} 4 \mathrm{~d})$ and erythrocyte-bound $\mathrm{C} 4 \mathrm{~d}(\mathrm{EC} 4 \mathrm{~d})$, within a multiparameter assay panel, may predict transition to SLE more than other lupus biomarkers. EC4d better correlates with lupus disease activity than low plasma complement levels. Elevated platelet-bound C4d (PC4d) correlates with thrombosis in SLE. Both EC4d and PC4d are increased in primary and secondary anti-phospholipid syndrome, and anti-beta2glycoproteinI antibodies may directly activate the complement system.

Summary Abnormal levels of plasma complement split products and CB-CAPs support complement activation as an important pathogenetic mechanism in SLE and the antiphospholipid syndromes. These tests show promise for the diagnosis of SLE and monitoring of disease activity.
\end{abstract}

Keywords Systemic lupus erythematosus $\cdot$ Complement $\cdot$ Complement activation measurement $\cdot$ Disease activity $\cdot$ Lupus nephritis

\section{Introduction}

It has been 120 years since the descriptions of the bactericidal activity in normal serum and the elucidation of the role of complement in normal human physiology and disease [1]. It is now known that the complement system consists of more than 30 plasma proteins and cell surface receptors involved in the activation and regulation of its

This article is part of the Topical Collection on Systemic Lupus Erythematosus

Arthur Weinstein

aw89@georgetown.edu

Loma Linda University, Loma Linda, CA, USA

Georgetown University, Washington, DC, USA

3 Exagen Inc., Vista, CA, USA lytic functions $[1,2]$. There are three pathways of complement activation (Fig. 1), all of which may be involved in systemic lupus erythematosus (SLE) inflammation and tissue damage, with the classical pathway, activated by antigen-antibody complexes, being the most important. The complement system has many biological functions in addition to bacteriolysis which may be important in SLE pathophysiology including promotion of inflammatory processes, clearance of immune complexes, and clearance of cellular and apoptotic debris [2]. Involvement of the complement system in SLE has been described by many investigators over the past 70 years with low levels of complement proteins $(\mathrm{C} 3, \mathrm{C} 4)$ and hemolytic activity having potential use as diagnostic markers for SLE and for monitoring disease activity [3-5]. However, limitations in using complement levels in SLE have been well documented [6,7]. Methods to detect complement activation in SLE and other conditions are shown in Table 1 (adapted from [7]). 


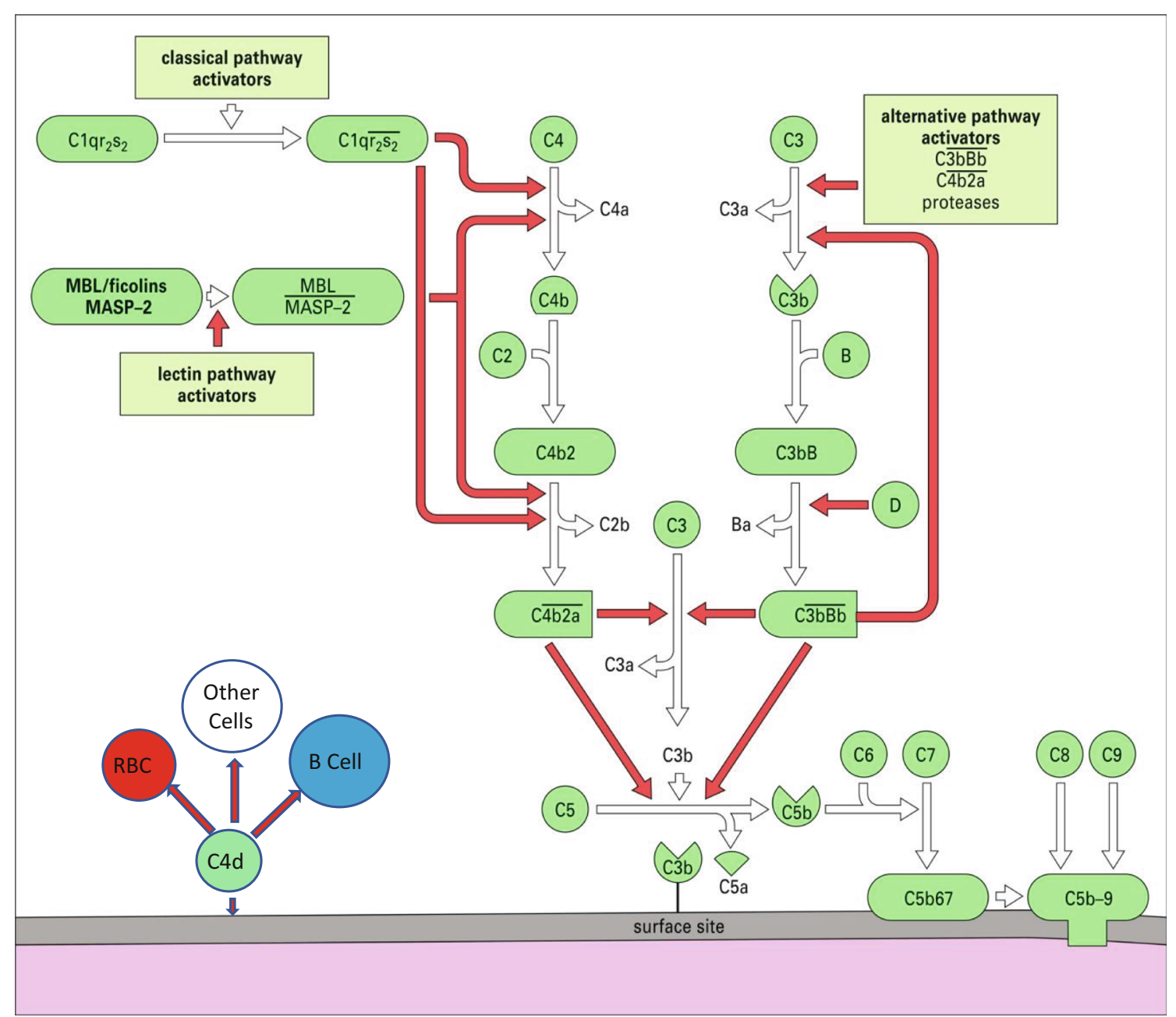

Fig. 1 Pathways of complement activation. Classical pathway activators include surface-bound IgG and IgM and circulating immune complexes. MBL mannose-binding lectin, MASP MBL-associated serine

This article will provide the current state of the art in the detection of complement activation in SLE since its last review in this journal [7]. We will review the use proteinases. Red arrows show feedback (amplification) loops. Modified from Morgan BP: Complement. In: Male D, Brostoff J, Roth DB, Roitt IM, editors. Immunology. 8th edition, Elsevier, 2012

of traditional complement proteins, $\mathrm{C} 3$ and $\mathrm{C} 4$, and compare them to complement activation (split) products in plasma and on cell surfaces in relation to their
Table 1 Detection of in vivo complement activation

\begin{tabular}{ll}
\hline Measurement & Example \\
\hline Individual complement plasma proteins & $\begin{array}{c}\mathrm{C} 3, \mathrm{C} 4 \text {, factor B, and other pathway proteins } \\
\text { decreased }\end{array}$ \\
Total hemolytic complement (snap frozen plasma) & $\mathrm{CH}_{50}$ decreased \\
Individual complement protein metabolism & $\mathrm{C} 3$ hypercatabolism \\
Deposit of complement proteins in tissues & $\begin{array}{l}\text { Detection of C3, C4, C1q, C4d, and } \\
\text { membrane attack complex (MAC, }\end{array}$ \\
& C5b-9) on glomeruli and skin \\
Plasma activation (split) products & basement membranes \\
& $\mathrm{C} 3 \mathrm{dg}, \mathrm{iC} 3 \mathrm{~b}, \mathrm{C} 4 \mathrm{~d}, \mathrm{MASP}-2, \mathrm{C} 5 \mathrm{a}, \mathrm{Bb}$, \\
Cell-bound complement activation & MAC, and others increased \\
products (CB-CAPs) & B cell C4d (BC4d), erythrocyte C4d \\
& (EC4d), and platelet-bound C4d \\
& (PC4d), among others, increased
\end{tabular}


application to SLE diagnosis and monitoring of disease activity.

\section{Plasma/Serum Complement Proteins as Markers of Complement Activation in the Diagnosis of SLE}

SLE is recognized as a disease where autoantibodies develop and fix to self-antigen resulting in complement activation and in turn leading to inflammation and tissue damage. Plasma complement levels can be influenced by a variety of factors: complement increases during the acute phase response, individual variability in complement gene copy number and expression, and variability in protein synthesis and catabolism. All these can influence plasma/serum complement levels [7]. Because of these factors, low complement levels perform poorly as diagnostic markers for SLE.

The SLE classification criteria modified over the years reflect the difficulty of utilizing serum complement levels. These criteria were developed for inclusion of SLE patients in research studies, and because of the poor sensitivity of low complement levels in lupus, the original criteria developed by the American College of Rheumatology did not have hypocomplementemia as a criterion [8]. The new classification criteria developed by the ACR and the European League against Rheumatism (EULAR) do include low plasma complement $\left(\mathrm{C} 3, \mathrm{C} 4 \mathrm{CH}_{50}\right)$, but partly because of expert opinion rather than statistical modeling [9].

In a European multinational inception cohort of 200 newly diagnosed (within two years) lupus patients, many of whom had active disease, low C3 and/or C4 levels were observed at baseline in 54\% [10]. Low complement levels are found even more infrequently in very early and milder disease. In a recent study of patients with probable lupus who fulfilled only three ACR criteria, only $36 \%$ had low C3 and/or C4 historically even though $30 \%$ transitioned to SLE at follow-up [11••].

\section{Complement Levels in the Monitoring of SLE Disease Activity and Lupus Nephritis}

Biomarkers of disease activity and flare must be studied longitudinally rather than cross-sectionally in lupus populations. With the interaction of complement proteins, receptors, inhibitors, and autoantibodies, this can be a complicated investigation. This is made more challenging by the variable natural history of SLE [12].

Low complement levels have proven disappointing as disease activity markers in general SLE because of both persistently low or normal levels, independent of disease activity, and insensitivity at predicting flares $[6,13,14 \bullet]$. Although the older studies suggest that low complement levels may reliably correlate with flares of lupus nephritis, this was not confirmed in a study of 71 lupus nephritis patients followed prospectively for about three years [15]. In the documented 70 flares, levels of $\mathrm{C} 3$ or $\mathrm{C} 4$ did not decrease in about one third of the patients giving a sensitivity of $\mathrm{C} 3$ and $\mathrm{C} 4$ for flare of $70 \%$ and $49 \%$, respectively. In a multivariate regression analysis, they showed that significant decreases in $\mathrm{C} 4$ did occur about two months before the renal flare in some patients. Also, a decrease in $\mathrm{C} 3$ that occurred at the time of flare was influenced by genotypic variation in factor $\mathrm{H}$, a regulator of $\mathrm{C} 3$ convertase in the alternative pathway. These data, which remain to be confirmed, indicate the complex involvement of complement activation in lupus nephritis and the limitations in using complement levels for disease monitoring. Another prospective study of 228 patients with lupus nephritis over six years showed that an increase in autoantibodies to $\mathrm{C} 1 \mathrm{q}$ outperformed low complement levels in the correlation with renal flares, especially in proliferative lupus nephritis, with $80.5 \%$ sensitivity and $71 \%$ specificity [16]. However, $20 \%$ of patients had a renal flare with normal anti-C1q levels and $30 \%$ in renal remission had high anti-C1q levels. Another longitudinal study demonstrated that a rising titer of both anti-C1q and anti-ds DNA together could predict a renal flare in some patients by many months [17].

\section{Complement Activation (Split) Products in the SLE Disease Monitoring and in Lupus Nephritis}

\section{Analyses of Plasma Split Products}

The above-described limitations of the complement proteins $\mathrm{C} 3$ and $\mathrm{C} 4$ as biomarkers for the diagnosis and monitoring of SLE disease activity have prompted the development of assays to measure the proteolytic fragments of complement proteins. As these fragments are formed upon activation of the complement cascade, complement split products reflect complement activation more accurately than the levels of the individual intact proteins.

Assays for several complement split products - either soluble or cell-bound - have been developed to evaluate whether these fragments can serve as biomarkers of SLE either to aid in the diagnosis of the disease or to monitor disease activity or as prognostic markers for flares of nephritis. There are technical issues related to detection of these split products in plasma. Many have a very short half-life. Also, some complement activation can occur in vitro at room temperature, even when collected in EDTA plasma tubes. Therefore, the split products must be measured within a short time on fresh plasma or the sample must be snap frozen until studied. These challenges have made these tests impractical for general clinical use outside of research laboratories [7]. However, the information 
gleaned from the recent studies described below adds to the accumulating evidence that complement activation in vivo in SLE is better detected by the presence of split products than by low complement protein levels.

Complement fragments derived from the classical pathway (C4d) or from the convergence of the three pathways of complement activation $(\mathrm{C} 3 \mathrm{dg}, \mathrm{iC} 3 \mathrm{~b})$ hold promise as biomarkers of SLE.

C3dg has a half-life of $4 \mathrm{~h}$ and can be measured in EDTA plasma frozen within a few hours of collection. Samples appear stable at $-80^{\circ} \mathrm{C}$ for a year, and values are not significantly affected by up to four freeze-thaw cycles. The assay for C3dg requires a step for the precipitation of larger C3 fragments. The supernatant can then be tested with the timeresolved immunofluorimetric assay or ELISA [18•]. Because the formation of split products in SLE happens in parallel with the degradation and synthesis of $\mathrm{C} 3$ during complement activation, the ratio $\mathrm{C} 3 \mathrm{dg} / \mathrm{C} 3$ has also been evaluated. The performance characteristics of $\mathrm{C} 3 \mathrm{dg}$ and the $\mathrm{C} 3 \mathrm{dg} / \mathrm{C} 3$ ratio have been compared with C3 levels in SLE and normal healthy subjects. Areas under the curve (AUC) of the receiver operating characteristics (ROC) are high at 0.96 and 0.89 , respectively, and much better than those of $\mathrm{C} 3$ levels; however, comparison of SLE versus other rheumatic diseases has not been performed [18•].

$\mathrm{iC} 3 \mathrm{~b}$ has a half-life of $90 \mathrm{~min}$. Samples of blood, plasma, or serum are placed within $30 \mathrm{~min}$ of venipuncture in a buffer that prevents spontaneous complement activation and are frozen immediately. The levels of $\mathrm{iC} 3 \mathrm{~b}$ and the $\mathrm{iC} 3 \mathrm{~b} / \mathrm{C} 3$ ratio are higher in SLE patients than in normal healthy subjects, and the SLE patients with active disease have $\mathrm{iC} 3 \mathrm{~b}$ and $\mathrm{iC} 3 \mathrm{~b} / \mathrm{C} 3$ ratio higher than patients with inactive disease. The AUC of the ROC curve of $\mathrm{iC} 3 \mathrm{~b} / \mathrm{C} 3$ is higher than that of $\mathrm{iC} 3 \mathrm{~b}$ in discriminating active and inactive SLE and flaring vs. nonflaring patients, and it outperformed $\mathrm{C} 3$ and $\mathrm{C} 4$ levels. In fact, the majority of patients with active SLE had high iC3b and $\mathrm{iC} 3 \mathrm{~b} / \mathrm{C} 3$ ratio whereas only $37 \%$ had low C3 levels [19•]. The quantitative lateral flow assay used in this study mitigates some of the handling issues with split product determination which can lead to in vitro complement activation [20].

C4d is a promising marker of disease activity in SLE as the delta change in plasma $\mathrm{C} 4 \mathrm{~d}$ values between low and high disease activities in a certain patient was higher for $\mathrm{C} 4 \mathrm{~d}$ than for $\mathrm{C} 3$ and $\mathrm{C} 4$ and the AUC of the ROC curve for high disease activity was higher for $\mathrm{C} 4 \mathrm{~d}$ than for $\mathrm{C} 3$ and $\mathrm{C} 4$ [21•]. In addition, $\mathrm{C} 4 \mathrm{~d}$ was higher in patients with nephritis than in patients without renal involvement. Of note, although the odds ratios of $\mathrm{C} 4 \mathrm{~d}$ were higher than those of $\mathrm{C} 3$ and $\mathrm{C} 4$, they were lower than those of dsDNA. The combination of anti-dsDNA and $\mathrm{C} 4 \mathrm{~d}$ was significantly associated with nephritis. In addition, data in a small number of subjects also indicate that $\mathrm{C} 4 \mathrm{~d}$ may be able to predict a lupus nephritis flare in patients who had already an episode of nephritis and, thus, are at increased risk. This study was conducted with plasma samples isolated from blood within $1 \mathrm{~h}$ of venipuncture and frozen within $2 \mathrm{~h}$. The ELISA was performed with an anti-C4d antibody that recognizes a neoepitope formed after $\mathrm{C} 4 \mathrm{~b}$ cleavage to $\mathrm{C} 4 \mathrm{~d}$. The same group also analyzed the $\mathrm{C} 4 \mathrm{~d} / \mathrm{C} 4$ ratio in a different patient population and found that both $\mathrm{C} 4 \mathrm{~d}$ and the $\mathrm{C} 4 \mathrm{~d} / \mathrm{C} 4$ ratio were higher in SLE patients - and especially in lupus nephritis - than in healthy controls [22••]. The AUC of the ROC curve of the $\mathrm{C} 4 \mathrm{~d} / \mathrm{C} 4$ ratio for lupus nephritis was 0.76 , higher than that of $\mathrm{C} 4 \mathrm{~d}$ and $\mathrm{C} 4$ alone (both 0.71 ). In addition, odds ratio analysis showed that high $\mathrm{C} 4 \mathrm{~d}$, low $\mathrm{C} 4$, and low $\mathrm{C} 3$ were associated significantly with nephritis with the $\mathrm{C} 4 \mathrm{~d} / \mathrm{C} 4$ ratio having the highest relative odds. Importantly, $\mathrm{C} 4 \mathrm{~d}$ and the $\mathrm{C} 4 \mathrm{~d} / \mathrm{C} 4$ ratio decreased in lupus nephritis patients who responded to therapy-while they did not change in nonresponders - and are associated with histopathological changes. The association with both clinical and histopathological responses in lupus nephritis suggests that the determination of $\mathrm{C} 4 \mathrm{~d}$ in plasma may at least partially replace invasive biopsies to evaluate active nephritis.

Limited data exists on soluble complement fragments derived from the lectin pathway. Some proteins of the lectin pathway are lower in SLE patients than in controls, while others have the opposite trend. In addition, some display a negative correlation with disease activity and a positive correlation with $\mathrm{C} 3$, indicating that consumption of some of the proteins of the lectin pathway occurs in SLE. In some studies, significant differences in concentrations between patients with SLE and controls have been observed, and in one study, there was a correlation of MASP-2 levels with SLE disease activity [23]. However, the wide range of the concentrations of these proteins in patients and controls makes their use as biomarkers of SLE uncertain at this time. Genetic deficiencies of mannose-binding lectin (MBL) have been associated with SLE [24].

\section{Cell-Bound Complement Activation Products (CB- CAPs) as Markers in SLE}

C4d as well as C3d is not only present in solution but also bound to the membrane of blood cells, such as erythrocytes, reticulocytes, B and T lymphocytes, and platelets. These complement fragments which are covalently bound to cell membranes are collectively called cell-bound complement activation products (CB-CAPs) [7]. They can be measured in EDTA-anticoagulated blood by flow cytometry, and their stability allows for samples to be shipped refrigerated to a central laboratory with overnight delivery. Although flow cytometry is labor intensive, sample processing in the clinic is minimal and does not require centrifugation or storage and transportation at low temperatures.

Extensive research has demonstrated the value of CBCAPs to aid in the diagnosis of SLE as well as to monitor 
disease activity, and a recent review on CB-CAPs in SLE has been published [25•]. In essence, $\mathrm{CB}-\mathrm{CAPs}$ are more sensitive than plasma/serum levels of $\mathrm{C} 3$ and $\mathrm{C} 4$ for the diagnosis of SLE. A more recent study showed that CB-CAPs (BC4d, EC4d) are more prevalent than low complement levels in patients with probable SLE $[11 \cdot 0]$ and when used in a multiparameter assay panel are better than other biomarkers at predicting transition to SLE.

We will review here recent data on $\mathrm{C} 4 \mathrm{~d}$ bound to erythrocytes (EC4d) and platelets (PC4d).

An analysis of three independent SLE populations showed that EC4d is associated with disease activity measured with the SELENA-SLEDAI or with the physician global assessment. Association is increased when EC4d is combined with low complement $\mathrm{C} 3 / \mathrm{C} 4$, indicating that both biomarkers have value in monitoring disease activity in SLE. Interestingly, in the majority of patients, serum complement levels did not change over time and were chronically low or chronically normal. In this subset, EC4d remained associated with disease activity, suggesting that EC4d is superior to $\mathrm{C} 3 / \mathrm{C} 4$ and can give information on disease activity in patients whose $\mathrm{C} 3 / \mathrm{C} 4$ does not reach abnormally low levels during high disease activity [14•].

Because of the increased risk of thrombosis in SLE, recent studies have evaluated whether CB-CAPs are associated with history of thrombotic events. EC4d has weak association, and $\mathrm{BC} 4 \mathrm{~d}$ is not associated with thrombosis. PC4d, however, has strong association with history of thrombosis (odds ratio $=$ 8.4). The association is particularly strong with venous thrombosis (odds ratio $=19.2$ ) and weaker with arterial thrombosis (odds ratio $=4.0$ ) $\left[26^{\bullet \bullet}\right]$. Multivariate logistic regression revealed that $\mathrm{PC} 4 \mathrm{~d}$, low $\mathrm{C} 3$, and lupus anticoagulant are all significantly and independently associated with thrombosis, indicating additive utility, especially for venous thrombosis.

Association of PC4d with history of thrombosis was recently found also by another group that analyzed PC4d by flow cytometry utilizing frozen platelet-rich plasma [27•] instead of fresh blood. Comparison of PC4d in patients with SLE to controls in the general population showed that PC4d was associated with venous thromboembolism and ischemic stroke, but not with ischemic heart disease or subclinical atherosclerosis. Interestingly, this study found not only a negative correlation between $\mathrm{PC} 4 \mathrm{~d}$ and $\mathrm{C} 3$ or $\mathrm{C} 4$ but also a positive correlation between $\mathrm{PC} 4 \mathrm{~d}$ and $\mathrm{C} 3 \mathrm{dg}$ and, to a lesser extent, with soluble C5a-9 [27•]. This suggests that both soluble and cell-bound complement split products may be useful biomarkers in SLE and may be associated with thrombosis. Complement-mediated thrombosis has been found in many complementopathies, even though the mechanisms remain unclear [28].

The ability of PC4d to predict the occurrence of cardiovascular events has yet to be demonstrated. In fact, prospective studies on thrombosis in SLE are particularly challenging owing to the relatively low number of events over a long period of time.

\section{Complement Activation with Other Lupus Features}

\section{Antiphospholipid Syndrome (APS)}

The risk of thrombosis in lupus depends on abnormalities such as known antiphospholipid antibodies (aPL), lupus anticoagulant, and nephrotic syndrome but as described above also markers of complement activation-low C3 and PC4d [26••]. Complement activation with hypocomplementemia is known to be associated with the primary APS as well as APS in SLE [29].

The link between thrombosis and complement activation was explored in two recent studies. Lonati and colleagues [30 showed that EC4d and PC4d were increased in primary and secondary APS and correlated with serum antibeta2glycoprotein 1 and anticardiolipin antibodies. They also showed that a monoclonal antibody against the D1 domain of anti-beta2glycoprotein 1 can bind in vitro to activated, but not resting, platelets leading to complement activation and deposition of $\mathrm{C} 4 \mathrm{~d}$ on the platelet surface. Although this study showed that C4d was deposited on a small percentage of platelets upon the addition of the autoantibody, it is tempting to speculate that immuno complexes containing anti-phospholipid and possibly other autoantibodies activate the complement cascade and lead to increased PC4d levels in patients whose platelets are not in a resting state. Thus, PC4d may be a marker of both complement and platelet activation in SLE. Another recent study provided evidence for complement activation in thrombotic APS as well as catastrophic APS (CAPS). It showed that antibeta2glycoproteinI antibodies activated complement directly and contributed to thrombosis whereas mutations in complement regulatory genes led to uncontrolled complement activation in CAPS [31・•].

Patients with SLE and/or APS are known to have an increased risk of adverse pregnancy outcomes (APOs) of fetal death, neonatal death, preterm delivery, and small gestational age infants. In a study of nearly 500 pregnant patients with SLE and/or antiphospholipid antibodies, patients with APOs showed increased levels of an alternative pathway split product, $\mathrm{Bb}$, as well as the terminal pathway component MAC (sC5b-9) early in pregnancy (12-15 weeks) [32••]. Alternative complement pathway activation is strongly implicated as a contributor to abnormal placental development and APOs.

\section{Thrombotic Microangiopathy (TMA)}

Thrombotic microangiopathy (TMA) is an endothelial injury that occurs in 1-4\% of lupus nephritis kidneys and is associated with severe morbidity and high mortality. Over half of lupus 
patients with TMA have complement regulatory protein mutations that have been associated with atypical hemolytic uremic syndrome (aHUS - microangiopathic hemolytic anemia, thrombocytopenia, and renal impairment). This has also been found in TMA associated with lupus nephritis [33]. Given the importance of complement fixation in lupus nephritis kidneys, a meta-analysis of complement inhibiting therapy in lupus nephritis with TMA was carried out. Fourteen studies were identified, with 30 patients included. TMA was determined either histologically or by aHUS diagnosis. All were treated with eculizumab, an inhibitor of C5 activation. A majority (28/30) of the patients had resolution of symptoms and recovery of renal function or were able to be discharged from the hospital. This underscores the interest in the development of complement inhibitory medications and the need for markers to determine which patients will benefit the most from them [34•].

\section{Complement Activation and Cell Function}

Activation of complement may affect the cells to which the activated products bind which might augment lupusrelated dysfunction and inflammation. C4d deposited on erythrocytes in trauma patients can decrease red cell deformability which could affect oxygen delivery to tissues [35]. C3d deposited on T cells in SLE results in greater production of cytokines - interferon gamma and interleukins 4 and 17 [36]. A recent review highlighted the role of the intracellular complement system (complosome) and its activation on $\mathrm{T}$ cell metabolism [37].

\section{Conclusion}

There is strong evidence that activation of the classical complement pathway by immune complexes in SLE is the terminal event leading to tissue damage in many organs. Despite this, low levels of C4 and C3 have limited diagnostic utility in SLE and poorly reflect disease activity. Newer studies measuring plasma complement split products and cell-bound activation products have suggested that elevated levels of these fragments are more useful diagnostic markers and more tightly correlate with SLE disease activity. Furthermore, there is growing evidence for the link between complement activation and thrombosis in SLE and in APS. With complement therapeutics gaining increasing use, it will be important to select those SLE patients who clearly have demonstrable evidence of complement activation and for whom this therapy may be most efficacious. Therefore, newer more reliable tests, as described in this review, may prove to be clinically useful.

\section{Compliance with Ethical Standards}

Conflict of Interest AW is a research consultant to Exagen Inc. He has received $>\$ 10,000$ stock options. RVA and DJA are employees of Exagen Inc.

Human and Animal Rights and Informed Consent This article does not contain any studies with human or animal subjects performed by any of the authors.

Open Access This article is licensed under a Creative Commons Attribution 4.0 International License, which permits use, sharing, adaptation, distribution and reproduction in any medium or format, as long as you give appropriate credit to the original author(s) and the source, provide a link to the Creative Commons licence, and indicate if changes were made. The images or other third party material in this article are included in the article's Creative Commons licence, unless indicated otherwise in a credit line to the material. If material is not included in the article's Creative Commons licence and your intended use is not permitted by statutory regulation or exceeds the permitted use, you will need to obtain permission directly from the copyright holder. To view a copy of this licence, visit http://creativecommons.org/licenses/by/4.0/.

\section{References}

Papers of particular interest, published recently, have been highlighted as:

- Of importance

•. Of major importance

1. Nesarkigar PN, Spiller B, Chavez R. The complement system: history, pathways, cascade and inhibitors. Eur J Microbiol Immunol. 2012;2:103-11. https://doi.org/10.1556/EuJMI.2.2012.2.2.

2. Walport MJ. Complement. First of two parts New Engl J Med. 2001;344:1058-66.

3. Vaughan JH, Bayles TB, Favour CB. The response of serum gamma globulin level and complement titer to adrenocorticotropic hormone $(\mathrm{ACTH})$ therapy in lupus erythematosus. J Lab Clin Med. 1951;37:698-702.

4. Schur PH, Sandson J. Immunologic factors and clinical activity in systemic lupus erythematosus. New Engl J Med. 1968;278:533-8. https://doi.org/10.1056/NEJM196803072781004.

5. Weinstein A, Bordwell B, Stone B, Tibbetts C, Rothfield NF. Antibodies to native DNA and serum complement (C3) levels. Application to the diagnosis and classification of systemic lupus erythematosus. Am J Med. 1983;74:206-16.

6. Esdaile JM, Abrahamowicz M, Joseph L, MacKenzie T, Li Y, Danoff D. Laboratory tests as predictors of disease exacerbations in systemic lupus erythematosus. Why some tests fail. Arthritis Rheum. 1996;39:370-8.

7. Liu C-C, Manzi S, Danchenko N, Ahearn JM. New advances in the measurement of complement activation: lessons of systemic lupus erythematosus. Curr Rheumatol Rep. 2004;6:375-81.

8. Tan EM, Cohen AS, Fries JF, Masi AT, McShane DJ, Rothfield NF. The 1982 revised criteria for the classification of systemic lupus erythematosus. Arthritis Rheum. 1982;25:1271-7.

9. Aringer M, Costenbader K, Daikh D, Brinks R, Mosca M, RamseyGoldman R, et al. 2019 European League Against Rheumatism/ American College of Rheumatology classification criteria for systemic lupus erythematosus. Arthritis Rheumatol. 2019;71:1400-12. 
10. Nossent J, Kiss E, Rozman B, Pokorny G, Vlachoyiannopoulos P, Olesinka M, et al. Disease activity and damage accrual during the early disease course in a multinational inception cohort of patients with systemic lupus erythematosus. Lupus. 2010;19:949-56. https://doi.org/10.1177/0961203310366572.

11.• Ramsey-Goldman R, Alexander RV, Massarotti EM, Wallace DJ, Narain S, Arriens C, et al. Complement activation in patients with probable systemic lupus erythematosus and ability to predict progression to American College of Rheumatology-classified systemic lupus erythematosus. Arthritis Rheumatol. 2020;72:78-88. https:// doi.org/10.1002/art.41093 This cross-sectional and longitudinal study showed that cell-bound complement activation products (CB-CAPs) are more prevalent than low complement levels in probable lupus and better predicted transition to SLE than other biomarkers.

12. Barr SG, Zonana-Nacach A, Madger LS, Petri M. Patterns of disease activity in systemic lupus erythematosus. Arthritis Rheum. 1999;42:2682-8.

13. Steinman AJ, Gladman DD, Ibanez D, Urowitz MB. Prolonged serologically active clinically quiescent systemic lupus erythematosus: frequency and outcome. J Rheumatol. 2010;37:1822-7. https:// doi.org/10.3899/jrheum.100007.

14. Merrill JT, Petri MA, Buyon J, Ramsey-Goldman R, Kalunian K, Putterman C, et al. Erythrocyte bound C4d in combination with complement and autoantibody status for the monitoring of SLE. Lupus Science \& Medicine. 2018:5e000263. https://doi.org/10. 1136/lupus-2018-000263 This compilation of three prospective studies demonstrated that EC4d is superior to low complement levels in monitoring disease activity in SLE.

15. Birmingham DJ, Irshaid F, Zou X, Tsao BP, Wu H, Yu CY, et al. The complex nature of serum $\mathrm{C} 3$ and $\mathrm{C} 4$ as biomarkers of renal flare. Lupus. 2010;19:1272-80.

16. Moroni G, Radice A, Giammarresi G, Quaglini S, Leoni A, Li Vecchi M, et al. Are laboratory tests useful for monitoring the activity of lupus nephritis? A 6-year prospective study in a cohort of 228 patients with lupus nephritis. Ann Rheum Dis. 2009;68: 234-7. https://doi.org/10.1136/ard.2008.094508.

17. Matrat A, Veysseyre-Balter C, Trolliet P, Villar E, Dijoud F, Bienvenue J, et al. Simultaneous detection of anti-Clq and antidouble stranded DNA autoantibodies in lupus nephritis: predictive value for renal flares. Lupus. 2011;20:28-34.

18. Troldborg A, Jensen L, Deleuran B, Stengaard-Pedersen K, Thiel S, Jensenius JC. The C3dg fragment of complement is superior to conventional $\mathrm{C} 3$ as a diagnostic biomarker in systemic lupus erythematosus. Front Immunol. 2018;9:1-10 This study optimized the method for measuring $\mathrm{C} 3 \mathrm{dg}$, a split product of $\mathrm{C3}$, and demonstrated that it was better than $\mathrm{C} 3$ in distinguishing SLE from normal control patients.

19. Kim AH, Strand V, Sen DP, Fu Q, Mathis NL, Schmidt MJ, et al. Association of blood concentrations of complement split product $\mathrm{iC} 3 \mathrm{~b}$ and serum C3 with systemic lupus erythematosus disease activity. Arthritis Rheumatol. 2019;71:420-30. https://doi.org/10. 1002/art.40747 This study demonstrated that iC3b, a C3 split product, and the $\mathrm{iC} 3 \mathrm{~b} / \mathrm{C} 3$ ratio better distinguish active from inactive SLE than $\mathrm{C} 3$ and $\mathrm{C} 4$ levels.

20. Schramm E, Staten N, Zhang Z, Bruce S, Kellner C, Atkinson JP, et al. A quantitative lateral flow assay to detect complement activation in blood. Anal Biochem. 2015;15:78-85.

21. Martin M, Smolag KI, Björk A, Gullstrand B, Okrój M, Leffler J, et al. Plasma C4d as marker for lupus nephritis in systemic lupus erythematosus. Arthritis Res Ther. 2017;19:266-75. https://doi.org/ 10.1186/s13075-017-1470-2 This study showed that C4d, an important split product in the classical complement pathway, as well as the $\mathrm{C} 4 \mathrm{~d} / \mathrm{C} 4$ ratio is associated with active lupus nephritis.
22.• Martin M, Trattner R, Nilsson SC, Björk A, Zickert A, Blom AM, et al. Plasma $\mathrm{C} 4 \mathrm{~d}$ correlates with $\mathrm{C} 4 \mathrm{~d}$ deposition in kidneys and with treatment response in lupus nephritis patients. Front Immunol. 2020;11:1-12. https://doi.org/10.3389/fimmu.2020.582737 This more recent study showed that $\mathbf{C} 4 \mathbf{d}$ is deposited in glomeruli in lupus nephritis, and a drop in the $\mathrm{C} 4 \mathrm{~d} / \mathrm{C} 4$ ratio correlated with the response of lupus nephritis to therapy.

23. Troldborg A, Thiel S, Trendelenburg M, Friebus-Kardash J, Nehring J, Steffensen R, et al. The lectin pathway of complement activation in patients with systemic lupus erythematosus. J Rheumatol. 2018;45:1136-44. https://doi.org/10.3899/jrheum. 171033.

24. Monticielo OA, Mucenic T, Xavier RM, Brenol JCT, Chies JAB. The role of mannose binding lectin in systemic lupus erythematosus. Clin Rheumatol. 2008;27:413-9. https://doi.org/10.1007/ s10067-008-0838-8.

25. Ramsey-Goldman R, Li J, Dervieux T, Alexander RV. Cell-bound complement activation products in SLE. Lupus Sci Med. 2017;4(1):e000236 This review highlighted literature on the use of CB-CAPs in SLE diagnosis.

26.• Petri MA, Conklin J, O’Malley T, Dervieux T. Platelet-bound C4d, low $\mathrm{C} 3$ and lupus anticoagulant associate with thrombosis in SLE. Lupus Sci Med. 2019;6(1):e000318 This study showed that PC4d may be an important marker for thrombosis in SLE.

27. Svenungsson E, Gustafsson JT, Grosso G, Rossides M, Gunnarsson I, Jensen-Urstad K, et al. Complement deposition, $\mathrm{C} 4 \mathrm{~d}$, on platelets is associated with vascular events in systemic lupus erythematosus. Rheumatology. 2020;0:1-11 This more recent study supported the prior study that high PC4d levels correlate with vascular events in SLE.

28. Gavrilaki E, Brodsky RA. Complementopathies and precision medicine. J Clin Invest. 2020;130:2152-63. https://doi.org/10.1172/ JCI/136094.

29. Oku K, Atsumi T, Bohgaki M, Amengual O, Kataoka H, Horita T, et al. Complement activation in patients with primary antiphospholipid syndrome. Ann Rheum Dis. 2009;68:1030-5. https://doi.org/10.1136/ard.2008.090670.

30. Lonati PA, Scavone M, Gerosa M, Borghi MO, Pregnolato F, Curreli D, et al. Blood cell-bound C4d as a marker of complement activation in patients with the antiphospholipid syndrome. Front Immunol. 2019;10:773 This study demonstrated that EC4d and PC4d were increased in APS and that a monoclonal antibody to beta2glycoprotein 1 induced deposition of $\mathrm{C} 4 \mathrm{~d}$ on the surface of activated platelets.

31.• Chaturvedi S, Braunstein EM, Yuan X, Yu J, Alexander A, Chen $\mathrm{H}$, et al. Complement activity and complement regulatory gene mutations are associated with thrombosis in APS and CAPS. Blood. 2020;135:239-51 This interesting study provided evidence that beta2glycoprotein antibodies activate complement directly providing a link between complement activation and thrombosis.

32.• Kim MY, et al. Complement activation predicts adverse pregnancy outcome in patients with systemic lupus erythematosus and/or antiphospholipid antibodies. Ann Rheum Dis. 2018;77:549-5. https:// doi.org/10.1136/annrheumdis-2017-212224 This study of a large number of pregnant SLE patients showed that elevated levels of the alternative pathway split product, $\mathrm{Bb}$, in the first trimester predict adverse pregnancy outcomes.

33. Park MH, Caselman N, Ulmer S, Weitz IC. Complement-mediated thrombotic microangiopathy associated with lupus nephritis. Blood Advances. 2018;2:2090-4. https://doi.org/10.1182/bloodadvances. 2018019596.

34. Wright RD, Bannerman F, Beresford MW, Oni L. A systematic review of the role of eculizumab in systemic lupus erythematosus-associated thrombotic microangiopathy. BMC Nephrology. 2020;21:245. https://doi.org/10.1186/s12882-020- 
01888-5 This review of uncontrolled but interesting studies showed that TMA-associated lupus nephritis might respond to the complement inhibitor, eculizumab.

35. Muroya T, Kannan L, Ghiran IC, Shevkoplyas SS, Paz Z, Tsokos $\mathrm{M}$, et al. C4d deposits on the surface of RBCs in trauma patients and interferes with their function. Crit Care Med. 2014;42:e364-72.

36. Borschukova O, Paz Z, Ghiran IC, Liu C-C, Kao AH, Manzi S, et al. Complement fragment $\mathrm{C} 3 \mathrm{~d}$ is colocalized within the lipid rafts of T cells and promotes cytokine production. Lupus. 2012;21: 1294-304

37. West EE, Kunz N, Kemper C. Complement and human T cell metabolism: location, location, location. Immunol Rev. 2020;295: 68-81.

Publisher's Note Springer Nature remains neutral with regard to jurisdictional claims in published maps and institutional affiliations. 